\title{
Sir Raymond WeST, K.C.I.E.
}

We regret to announce the death of Sir Raymond West, K.C.I.E., Hon. Vice-President and late Director of the Society, which took place on September 8 in his 80 th year.

A full obituary notice will appear in the next number of the Journal. 